\title{
Insulin protects cognitive function in experimental stroke
}

\author{
A J Strong, J E Fairfield, E Monteiro, M Kirby, A R Hogg, M Snape, L Ross-Field
}

\begin{abstract}
There is evidence from in vitro systems that the extent of neuronal loss in acute central nervous system ischaemia can be reduced by manoeuvres which restrict availability of glucose to the ischaemic area. Experiments were designed to test whether hypoglycaemia induced with insulin is associated with improved behavioural outcome in a recovery model of stroke. Rats learned a maze task as a test of working memory, believed to be subserved by the hippocampus, and then had a period of cerebral ischaemia, followed by reperfusion. After an interval of 14 days they were tested on the same maze, where lesioned animals had very significant ( $p$ $<0.0001$ ) impairment of working memory, whereas lesioned and treated $\left(2.0 \mathrm{u} / \mathrm{kg}^{-1}\right.$ insulin, minimum single plasma glucose value: $3 \cdot 1 \mathrm{mmol} / \mathrm{1}^{-1}$ ) animals were indistinguishable from control animals. It is concluded that a striking degree of protection can be obtained with levels of mild hypoglycaemia which may be acceptable and practicable for use in humans.
\end{abstract}

The association of brain acidosis with adverse outcome from stroke is widely recognised, particularly in the experimental field, and dates from work by Myers et al in $1976 .{ }^{1}$ They found first that primates undergoing temporary occlusion of the ascending aorta survived if fasted before the procedure, whereas those allowed free access to food recovered initially but later died, with signs of brain swelling and brain stem compression. They later found that fatal outcome was associated with development of brain lactate concentrations in excess of $20 \mu \mathrm{mol} / \mathrm{g}$ wet weight $^{-1}$, and attributed the difference to reduction by fasting of plasma glucose and its availability to the brain. ${ }^{2}$ The role of glucose availability to the ischaemic brain in determining the extent of acidosis, and the relationship of acidosis with metabolic reversibility and histopathological changes, was further examined by Rehncrona and Siesjo et al, ${ }^{34}$ who also suggested that the poorer outcome from incomplete as opposed to complete cerebral ischaemia was due to promotion of acidosis by relative maintenance of delivery of glucose. Information from the United States Stroke Data Bank analysed by Mohr et al suggests a similar relationship in humans. Raised blood sugar on admission was associated with increased mortality: the principal increase occurred with an increase in blood sugar to above $5.55 \mathrm{mmol} / \mathrm{1}^{-1}$, whereas mortality rose less strikingly with further increases in admission blood sugar. Normoglycaemia appeared to provide sufficient glucose delivery to permit the development of acidosis.

Several biochemical treatment strategies have been explored experimentally in an effort to restrict development of brain lactic acidosis. We first confirmed the therapeutic potential of mild insulin induced hypoglycaemia in 1985: mild hypoglycaemia (3.0-4.5 $\left.\mathrm{mmol} / \mathrm{1}^{-1}\right)$ was shown partially to protect brain mitochondrial respiration in unilateral forebrain ischaemia in the rat. ${ }^{6}$ Robertson and Grossman ${ }^{7}$ were able to show significant improvement in recovery of spinal cord acidosis and function (evoked potential amplitude) in rabbits undergoing transient spinal cord ischaemia and receiving insulin.

LeMay et $a l^{\beta}$ have recently demonstrated improved survival and neurological performance in rats subjected to cerebral ischaemia and receiving $1.7 \mathrm{u} / \mathrm{kg}^{-1}$ insulin one hour before a period of 20 minutes of cerebral ischaemia, compared with those receiving intraperitoneal saline. For reasons given in our discussion, we believe these results should be regarded as an encouraging preliminary result, but not as a definitive study demonstrating protection of behavioural outcome against the effects of ischaemia, opposed to simply the experimental procedure.

This study was designed to meet the need for evidence that mild hypoglycaemia improves behavioural or neurological outcome in an experimental model of stroke, as an essential preliminary to a clinical study. Rats learned a maze task, and were then subjected to transient forebrain ischaemia, by bilateral carotid occlusion combined with haemorrhagic hypotension. In the treatment group, intraperitoneal insulin was used to induce mild hypoglycaemia to a target minimum plasma glucose concentration of $3.0 \mathrm{mmol} / \mathrm{1}^{-1}$. After allowing 14 days for recovery, memory was re-examined using the same maze task.

\section{Methods}

Assessment of memory using the radial arm maze

The radial arm maze has been validated as a tool for the investigation of spatial memory, and its use to examine the memory changes occurring after a period of global cerebral ischaemia has been described. ${ }^{111}$ Briefly, it 
consists of a $0.6 \mathrm{~m}$ diameter circular central platform standing $1 \mathrm{~m}$ above floor level, from which eight $0.6 \mathrm{~m}$ long arms radiate. At the end of each arm is a cup into which a food pellet can be placed; visual cues are placed around the room, to allow orientation.

Fifty male Wistar rats weighing $200-250 \mathrm{~g}$ were handled daily for one week to familiarise them with the trainer; subsequently they were fed only sufficient food each morning to maintain them at $85 \%$ of their initial body weight. Over the next week they were gradually introduced to the radial arm maze until at the end of the second week there was only one food pellet in the cup at the end of five of the eight arms. The rats were tested three times per day on the maze. Before each trial one food pellet was placed in five of the eight food cups, the rat was placed in the centre of the maze, and then allowed to run the maze until either: 1) it had taken all the food pellets, or 2) it had made 16 arm entries, or 3 ) it had spent 10 minutes on the maze.

During each trial a note was made of each arm entered and the time taken to complete the trial. If the rat re-entered an arm from which it had already taken the food pellet it scored one working memory error. If it entered an arm which never contained food it scored one reference memory error, and if it re-entered that arm it scored a combined working and reference memory error.

Each day following training the rats were weighed, and their general physical condition assessed. After 18 days of training on the maze 48 of the 50 rats had reached a performance target of less than one working, and one reference memory error per trial, and these animals continued to the next stage of the experiment.

\section{Design of the trial}

Rats were randomly allocated to one of four groups:

Untreated sham (US) control group for anaesthesia and surgery (10 animals).

Untreated ischaemic (UI): to observe the effects of ischaemia on behaviour without treatment ( 17 animals).

Insulin treated sham (TS): to measure any effects treatment might have on normal animals (eight animals).

Insulin treated ischaemic (TI): to measure any effects treatment might have on ischaemic animals (13 animals).

\section{Plasma glucose management}

The rats were allowed free access to food and water until 75 minutes before surgery, when groups $T I$ and $T S$ received a single intraperitoneal injection of $2 \mathrm{u} / \mathbf{k g}^{-1}$ neutral insulin (Human Actrapid, Novo), while groups UI and US received an equivalent volume of isotonic saline.

\section{Surgical preparation}

After 18 days of training on the radial arm maze, cerebral ischaemia was produced by the two vessel occlusion method. ${ }^{12}$ Anaesthesia was induced with $70 \%$ nitrous oxide and $2 \%$ halothane in oxygen. The trachea was intubated and ventilation of the lungs commenced with $70 \%$ nitrous oxide and $1 \%$ halothane in oxygen at a tidal volume of 15 $\mathrm{ml} / \mathrm{kg}^{-1}$ and a respiratory rate of 60 using a rodent ventilator. Muscular paralysis was achieved with an intraperitoneal injection of suxamethonium $1 \mathrm{mg} / \mathrm{kg}^{-1}$, repeated as required.

A polythene cannula was inserted into the tail artery for monitoring of arterial pressure and gases.

Both carotid arteries were surgically exposed through a single incision in the neck and the vagus nerves carefully dissected clear. Braided silk was looped around the arteries to enable their later occlusion. The right internal jugular vein was then cannulated, to allow the administration of drugs and the withdrawal of blood for hypotension.

When the surgical preparation had been completed the animal was anticoagulated with $200 \mathrm{u} / \mathrm{kg}^{-1}$ heparin, the halothane discontinued, and anaesthesia maintained with $70 \%$ nitrous oxide in oxygen.

\section{Cerebral ischaemia}

After an interval of 30 minutes to stabilise the preparation, blood was withdrawn from the internal jugular vein until the mean arterial pressure was $80 \mathrm{mmHg}$. In those animals in which cerebral ischaemia was required (UI + TI), both carotid arteries were then occluded by tightening the snares around them, and the blood pressure further lowered by venesection to a mean of $50 \mathrm{mmHg}$. The blood pressure was maintained at $50-55 \mathrm{mmHg}$ for a period of exactly ten minutes by gentle removal and infusion of blood as necessary. At the end of this period all the withdrawn blood was infused, and the carotid snares were released.

\section{Sham surgery}

In the control animals which were subjected to surgery but not to cerebral ischaemia (US + TS), the same procedure was followed, including hypotension to $50 \mathrm{mmHg}$, but the snares around the carotid arteries were not tightened.

\section{Recovery from anaesthesia}

In all animals $2 \mathrm{mmol} / \mathrm{kg}^{-1}$ sodium bicarbonate $(8.4 \%)$ was given intravenously following return of blood pressure to normal to correct the acidosis produced by the period of hypotension, with additional supplements as required depending upon blood gas estimations; the internal jugular line was then removed, and the neck incision closed. The tail artery catheter was removed last. Ventilationwith $70 \%$ nitrous oxide in oxygen was continued until good respiratory effort had returned at which point the rat was ventilated with $100 \%$ oxygen and the tracheal tube removed when purposeful movements had returned. It was then returned to its cage and given free access to food and water.

\section{Convalescence}

Following surgery the rats were weighed, and their general condition observed daily. All the 
Figure 1 Mean plasma glucose concentrations measured at four stages of the surgical procedure (groups UI, US, TI, TS with upper $95 \%$ confidence interval): 1) immediately following insertion of the arterial line, 2) before starting the stabilisation period, 3) two minutes following cerebral reperfusion, 4) immediately before removal of the arterial line.

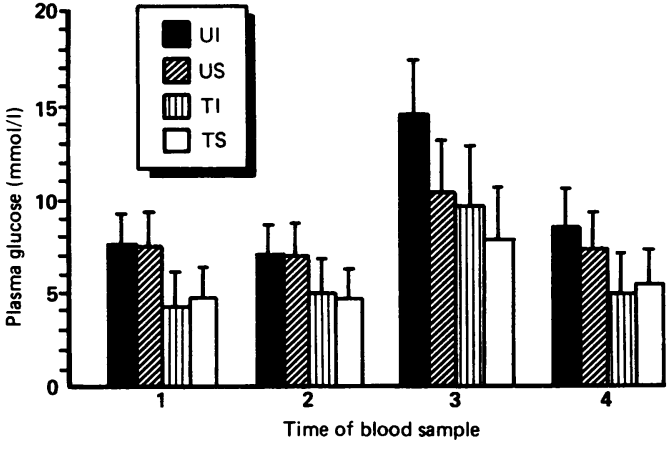

rats that were unable to eat or drink, or were otherwise suffering from obvious neurological disorder were removed from further study. After a period of 14 days the remainder had repeat testing on the radial arm maze.

Blood samples

Four blood samples of $0.3 \mathrm{ml}$ were taken from the arterial line into a heparinised syringe: 1) Immediately following insertion of the arterial line, 2) Before starting the stabilisation period, 3) Two minutes following cerebral reperfusion, 4) Immediately before removal of the arterial line.

One third of the sample was used for immediate estimation of blood gases (Instrumentation Laboratories 1304), and the remainder was centrifuged and the plasma frozen for glucose estimation later (Yellow Springs Instruments).

\section{Results}

Mortality

Of the $\mathbf{4 8}$ animals that had surgery nine died for technical reasons (for example, accidental extubation, or haemorrhage) before the period of hypotension, and these were withdrawn from the trial, leaving 39 animals. Having undergone ischaemia or sham surgery, eight animals failed to recover from anaesthesia; US $\mathrm{n}=1$, UI $\mathrm{n}=2, \mathrm{RS} \mathrm{n}=2$, TI $\mathrm{n}=3$. During the period of convalescence one animal from group US was withdrawn from the trial following tail necrosis, and six animals died of neurological complications; US $\mathrm{n}=0, \mathrm{UI} \mathrm{n}=$ 4 , TS $n=0$, TI $n=2$. The number of deaths in each group was compared using the Chi squared test for the effects of ischaemia (UI + TI vs US + TS) and insulin treatment (TI + TS versus UI + US). No significant differences were found either for those failing to recover from anaesthesia, or for those that died during the period of convalescence. Behavioural testing on the radial arm maze was performed on the remaining 24 animals.

\section{Plasma glucose}

The mean plasma glucose levels for each group, at each time period are shown in fig 1 . Two way analysis of variance was performed on this data taking $\mathrm{n}$ to be the number of animals alive in each group at that time (so that a deleterious effect due to severe hypoglycaemia was not missed). This analysis showed that at all time points plasma glucose was significantly lower in
Figure 2a, $b$ Exponential regression lines (with $95 \%$ confidence limits) of the number of reference $(a)$ and working (b) memory errors made by each group of rats following surgery.

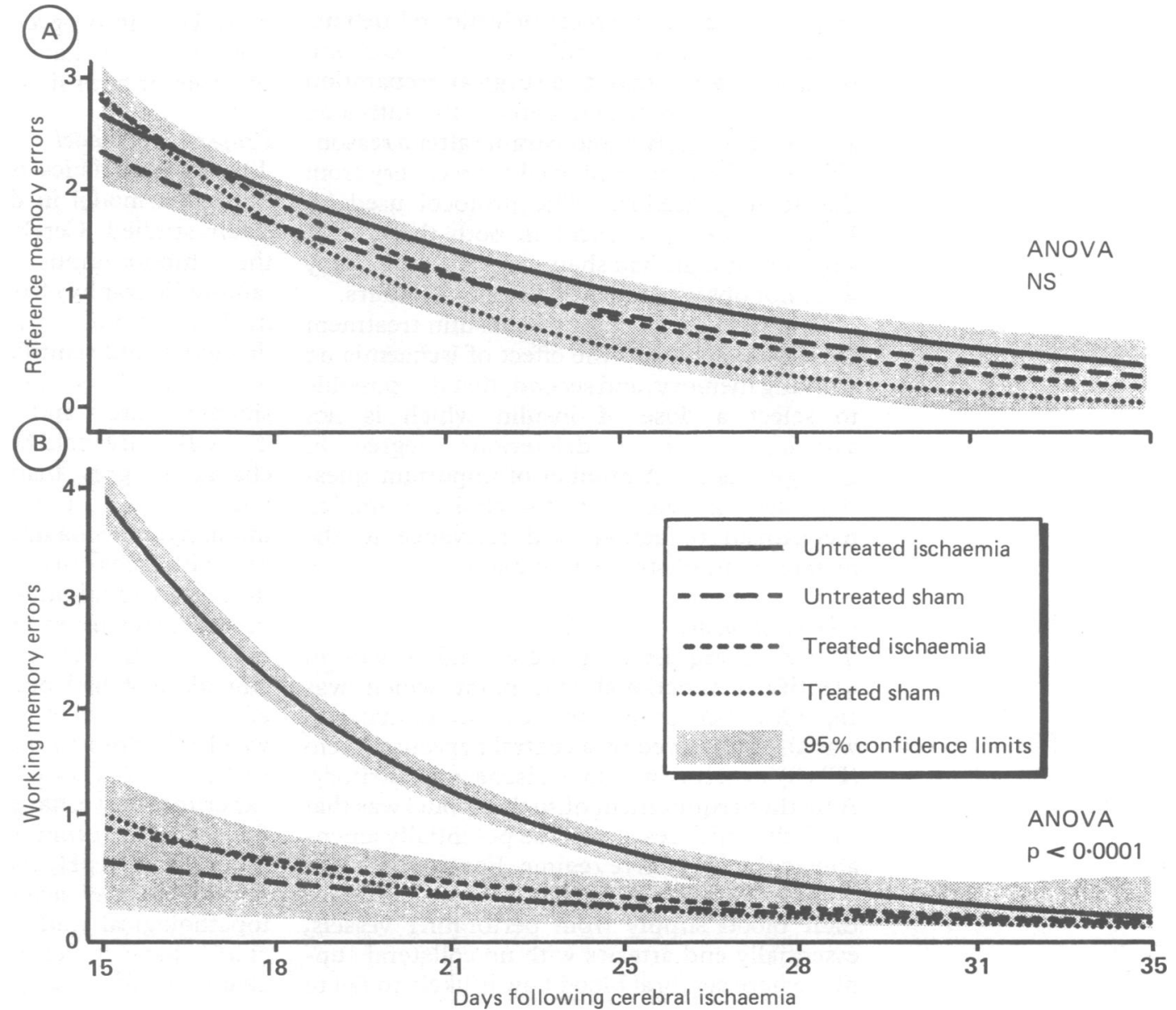


the insulin treated groups compared with the untreated groups, and that at points 1,2 , and 4 the differences could be accounted for by insulin treatment $(\mathrm{p}<0.01)$. At time point ? (immediately after the induction of cerebra ischaemia) the plasma glucose was increased in all four groups as a result of hypotension. The effects of ischaemia caused an increase in plasma glucose $(p<0.05)$, which was partially controlled in those groups receiving insulin treatment ( $p<0.02)$, although there was no significant two way interaction between the groups.

\section{Memory}

Two-way analysis of variance of the number of reference and working memory errors made by the rats after surgery was made. There was no significant difference in reference memory between any combinations of the groups, but for working memory the difference between the groups was highly significant $(p<0.0001)$. Multiple range analysis clearly confirmed that the difference was between UI and the other three groups. Because the day-to-day variation in behaviour of the animals makes interpretation of raw learning curve data difficult, the results are presented as the exponential regression lines calculated by the method of least squares for the mean number of errors made by each group of rats for both reference and working memory (fig $2 a, b$ ).

\section{Discussion}

To our knowledge this paper is the first demonstration that insulin-induced hypoglycaemia, or insulin per se, corrects behavioural deficits which are unequivocally due to cerebral ischaemia rather than to a surgical preparation artefact, and in which defects in untreated animals are clearly demonstrable after a reasonable period has been allowed for recovery from the acute procedure. The protocol used by LeMay et $a l^{\beta}$ is deficient in both these areas since no animals had sham-occlusion, and they were not observed for longer than 24 hours.

Our results show first that insulin treatment effectively abolishes the effect of ischaemia on working memory, and second, that it is possible to select a dose of insulin which is not associated with a deleterious degree of hypoglycaemia. A number of important questions arise in relation to the choice of model, mechanism of action, and relevance to the management of stroke in humans.

Choice of model

The first requisite in these studies was to identify a functional end point which was capable of being tested in the intact animal, and was also subserved by a central nervous system (CNS) structure within the ischaemic territory. A further requirement of such a model was that the ischaemic area should be potentially amenable to the protective regime. For example, the corpus striatum and internal capsule receive their blood supply from perforating vessels, essentially end arteries with no collateral supply, where cerebral blood flow is likely to fall to very low levels with almost any form of ischaemic insult. Hyperglycaemia has an adverse effect on evolution of ischaemia where perfusion is partially maintained by collateral circulation, ${ }^{13}$ but protects in end-vessel ischaemia. ${ }^{14}$ Core levels of ischaemia are associated with homogeneous and irreversible infarction, and no form of treatment can be expected to improve outcome. In principle, a middle cerebral artery occlusion (MCAO) model which, at least in the cat and primate, appears to be associated with an area of potentially salvageable cortex, the "ischaemic penumbra", would be suitable. However, for the purposes of this experiment a small animal model capable of being studied behaviourally in sufficient numbers was required, and the volume of cortical penumbra available in the rat MCAO model has not been established. Moreover, the precise cognitive or functional correlates of any cortical preservation that might be achieved in this model are unclear.

Our choice of model meets the requirements in that cerebral ischaemia produced by the method described has been shown to reliably produce hippocampal damage. ${ }^{15}$ Although the precise function of the hippocampus is still unclear it is known to be important in certain aspects of memory. ${ }^{16-18}$ Behavioural testing of the intact animal has been demonstrated to be a sensitive indicator of hippocampal damage, ${ }^{10}$ and also offers the advantage of being amenable to protection with other agents. ${ }^{19}$

Although hippocampal damage is a prominent feature of the transient forebrain ischaemia model in the rat, scattered neocortical damage is also seen. Histological examination of our material is in progress, and our results, which relate only to behaviour, may reflect protection of either or both sites.

\section{Properties of model}

The characteristics of the forebrain cerebral ischaemia model in the rat have been extensively studied. Cerebral blood flow (CBF) in the hippocampus fell in one study (autoradiography) from approximately 90 to 1 $\mathrm{ml} / 100 \mathrm{~g}^{-1} / \mathrm{min}^{-112}$ and in another (CBF by dissection and scintillation counting) from 149 to $33 \mathrm{ml} / 100 \mathrm{~g}^{-1} / \mathrm{min}^{-115}$. There was considerable inter- and intra- animal variability. The CBF threshold below which ischaemic cell change in grey matter in the rat becomes unequivocal is $24 \mathrm{ml} / 100 \mathrm{~g}^{-1} / \mathrm{min}^{-1}$. 20 There is initial hyperaemia upon reperfusion, but in fed rats with ischaemia of identical severity to our model but 15 minutes duration, CBF falls later in the reperfusion phase to $28 \mathrm{ml} / 100 \mathrm{~g}^{-1} /$ $\min ^{-1} \cdot .^{12}$ In the fronto-parietal cortex of animals that had been fed, brain lactate rose after 15 minutes of ischaemia to $19.5 \mu \mathrm{g} / \mathrm{g}$ wet weight $^{-1}$, close to the critical value identified earlier by Myers et al In separate, limited experiments we have used the umbelliferone fluorescence technique ${ }^{21}$ for measurement of regional tissue $\mathrm{pH}$, and were able to confirm the development of acidosis in this model. Histopathological studies of the model by Swann et $a l^{15}$ have revealed mild hyperchromatic change in the cytoplasm of less than $10 \%$ of 
hippocampal pyramidal neurons after $10 \mathrm{~min}$ utes of ischaemia, but after 24 hours of reperfusion, all cells in the hippocampal CA1 region were abnormal, and there was extensive perineuronal oedema. In starved animals, changes after 24 hours of reperfusion were mild to moderate, but at seven days there was marked deterioration in or loss of CAl neurons, but improvement in other regions of the brain.

Microdialysis methods have demonstrated that in the hippocampus during ischaemia there are increases in the extracellular concentration of glutamate, a major CNS excitatory amino acid neurotransmitter. ${ }^{22}$ The density of $\mathrm{N}$-methyl-D-aspartate (NMDA) receptors (one class of glutamate receptor) is high in the CA1 region of the hippocampus. ${ }^{23}$ NMDA receptors activate post-synaptic channels with high $\mathrm{Ca}^{2+}$ permeability. ${ }^{24}$ Micro-electrode recordings from the $\mathrm{CA} 1$ region indicate continued post-ischaemic burst firing, ${ }^{25}$ extracellular calcium concentration falls during ischaemia ${ }^{26}$ and intracellular deposits of calcium appear in mitochondria (electron microscopy). ${ }^{27}$ Hippocampal ischaemic damage can be reduced by deafferentationof the CA 1 region. ${ }^{28}$ The pattern therefore emerges of progressive CA1 neuronal loss during the days following the period of ischaemia, promoted by sustained, abnormal neuronal activity which results in high intracellular, and probably cytotoxic, concentrations of free calcium ions.

The pattern of hippocampal pathology present in this model, particularly its delayed evolution, is by no means characteristic of acute neocortical ischaemia as it presents in primates. Our model is most directly relevant in the case of hippocampal damage resulting from hypoperfusion from any cause, including cardiac arrest, ${ }^{29}$ surgery and anaesthesia, ${ }^{30} 31$ as well as occlusive lesions. In such patients coming to post-mortem the loss of neurons from the CA1 region is striking, as is short term spatial memory loss. ${ }^{17}$ However, the main purpose of our model was not to replicate any particular combination of deficits as seen clinically, but to establish that the protective regime has produced improvements in neurological function within the ischaemic territory.

Selective ischaemic damage to working but not reference memory

The generally accepted definitions of working and reference memory are that working memory involves the use of trial-unique information (that is, retention is only required over a short period), while reference memory involves the use of cross-trial information (that is, retention is required over a long period).

Our failure to demonstrate any detrimental effect of ischaemia on reference memory, and the observed adverse effect of ischaemia on working memory in the untreated groups with pre-lesion training, extend the findings of Davis et al. ${ }^{11}$ They showed that global cerebral ischaemia followed by behavioural training (without pre-lesion training) also has detrimental effects on working, but not reference memory. Their data suggest that ischaemic damage to the hippocampus affects the initial processing of working memory, while our data suggest that long term maintenance of working memory is also affected.

Barnes in his review of hippocampal lesions ${ }^{16}$ suggested that as damage to spatial memory is reduced by increasing the length of time between the end of behavioural training and hippocampal insult, spatial information must become at least partially independent of the hippocampus given sufficient time. Our data would suggest that 14 days is insufficient time for working memory to become independent of the hippocampus.

The pattern of temporally restricted retrograde amnesia that we have found bears marked similarities to the characteristic syndrome associated with damage to the human hippocampal formation following an ischaemic, or hypoxic insult. ${ }^{31} 32$

\section{Mechanism of protection}

We believe that the most likely mechanism of action of insulin in this model is to increase glucose transport from blood into muscle and fat, hence reducing plasma glucose and therefore glucose availability to the brain. We studied only a single dose of insulin, $2 \mathrm{u} / \mathrm{kg}^{-1}$, which we selected on the basis that levels of plasma glucose lower than those resulting from the use of this dose have been found to impair recovery following cerebral ischaemia, ${ }^{33}$ and would not be contemplated in clinical management. LeMay et al, using a different insulin preparation, obtained optimal survival and significant improvement in neurological deficit score with 0.4 units regular insulin (approximately $1.7 \mathrm{u} / \mathrm{kg}^{-1}$ ) with a minimum plasma glucose two hours after intraperitoneal insulin of $3.33(0.39) \mathrm{mmol} / \mathrm{1}^{-1}$, mean (SEM). With higher doses of insulin $\left(2 \cdot 1\right.$ and $\left.2.5 \mathrm{u} / \mathrm{kg}^{-1}\right)$, mortality rose.

Two other mechanisms of action are possible, but both are highly speculative. First, the presence of insulin binding sites in the brain is well established, ${ }^{34}$ especially in the limbic system, and insulin might have a specific action at these sites independent of its effect on blood glucose, with primary or secondary protective effects in the hippocampus similar to those of a lesion in an afferent pathway such as the perforant path. ${ }^{28}$ Second, evidence for an insulin stimulated $\mathrm{Na}^{+} / \mathrm{H}^{+}$antiporter system in muscle has recently been obtained. ${ }^{35}$ However, we know of no evidence at present for a similar system in the brain.

Our findings, although they support the general concept of neuronal protection by restriction of glucose availability, may be regarded as less expected in the case of the hippocampus than in cerebral cortex. Delayed neuronal loss in the hippocampus following transient forebrain ischaemia has been regarded as $\mathbf{C a}^{2+}$ dependent, for the reasons given above, and protection can be achieved with calcium antagonists. ${ }^{193637}$ We know of no established hippocampal protective regimes with a suggested mechanism of action depending on control or manipulation of $\mathrm{H}^{+}$or $\mathrm{Na}^{+}$homeostasis.

Why then should restriction of acidosis also 
confer protection? It is believed that ischaemic increases in cytosolic free proton concentration, in either neurons or glia, are buffered in part by the operation of a plasma membrane based $\mathrm{Na}^{+} / \mathrm{H}^{+}$antiporter, ${ }^{38}$ driven by the movement of sodium ions down their normal electro-chemical concentration gradient, which is in turn maintained by $\mathrm{Na}, \mathrm{K}, \mathrm{ATPase}$ activity. $\mathrm{A} \mathrm{Na} \mathrm{Na}^{+} / \mathrm{Ca}^{2+}$ antiporter also exists, ${ }^{39}$ apparently dependent on the same gradient for $\mathrm{Ca}^{2+}$ extrusion, and probably contributing to the homeostasis of increases in free cytosolic calcium due to ischaemia. It seems likely that homeostasis of cytosolic $\mathrm{pH}$ and calcium concentration both depend on the maintenance of the same sodium gradient. We are thus drawn to the same conclusion as Hakim, ${ }^{40}$ that if a particular therapeutic regime, for example a calcium channel blocking agent, successfully restricts this source of load on the sodium gradient, then the potential energy of the gradient is available for other antiporter systems, and in this example a reduction of intracellular acidosis might be predicted. Such a mechanism would explain the improvement in ischaemic brain $\mathrm{pH}$ with the calcium channel blocking agent nimodipine in the rat MCAO model without improvement in CBF observed by Berger and Hakim. ${ }^{41}$ In the case of our own experiments, partial maintenance of neuronal $\mathrm{pH}$ (if confirmed) would reduce turnover at the $\mathrm{Na}^{+} / \mathrm{H}^{+}$antiporter making the sodium gradient available for intracellular calcium homeostasis by the $\mathrm{Na}^{+} / \mathrm{Ca}^{2+}$ system.

\section{Application in humans}

The potential applicability of these findings and of those of LeMay and colleagues is limited by the fact that in all cases insulin has been given before the start of ischaemia. We know of no study where insulin given after onset of ischaemia has been shown to be beneficial.* However, the delayed onset of ischaemic complications of aneurysmal subarachnoid haemorrhage (SAH), and profound hypotension during anaesthesia, (for example where cardiopulmonary bypass is used), represent situations in humans where careful control of plasma glucose within the range 3.5-4.5 $\mathrm{mmol} / \mathrm{1}^{-1}$ would seem appropriate and could be implemented before the onset of ischaemia. The clinical data ${ }^{5}$ suggest that values above $5 \cdot 0$ $\mathrm{mmol} / \mathrm{1}^{-1}$ will not confer protection. The demonstrations by LeMay et al and ourselves of protection with levels of plasma glucose for the most part greater than $3.5 \mathrm{mmol}^{-1}$ suggest that a glucose clamping technique aiming for a range of $3.5-4.5 \mathrm{mmol} / 1^{-1}$ would leave an adequate safety margin.

We believe that a good case can be made for a prospective study of glucose clamping to the region of $3.5-4.5 \mathrm{mmol} / 1^{-1}$ in patients with acute cerebral ischaemia. Our preliminary assessment of this method in patients with SAH suggests that it is practicable and safe, but much further experience in its use will be required, and we believe that a controlled, randomised study may become necessary.

In the light of increasing evidence of the beneficial effect of nimodipine, it is likely that a high proportion of SAH patients will in future receive nimodipine. If the suggestion that antiporter mechanisms compete for the $\mathrm{Na}^{+}$ gradient is correct, it is by no means certain that patients receiving nimodipine would derive additional benefit from mild hypoglycaemia. Although in the recent British Aneurysm Trial $^{42}$ the incidences of poor outcome and of definite or probable stroke were reduced by nimodipine, the approximate incidence of these end-points of $20 \%$ in patients receiving nimodipine remains significant, and the potential value of mild hypoglycaemia requires assessment.

We believe that our findings represent an encouraging development in approaches to the management of acute cerebral ischaemia, and provide a basis for the design of a prospective, controlled study.

*Note added in proof:

Voll et $a l^{1}$ have studied a model almost identical with ours and demonstrated that post ischaemic insulin reduces spatial learning deficits significantly. Pre-treatment with insulin in gerbils undergoing unilateral common carotid artery occlusion for four hours has been shown by Fukuoka et $\mathrm{al}^{2}$ to be beneficial: their end points were neurological deficit and histology.

1 Voll CL, Whishaw IQ, Auer RN. Postischemic insulin reduces spatial learning deficit following transient forebrain ischemia in rats. Stroke 1989;20:646-51.

2 Fukuoka S, Yeh $\mathrm{H}$, Mandybur TI, Tew JM Jr. Effect of insulin on acute experimental cerebral ischemia in gerbils. Stroke 1989;20:396-9.

We thank Action Research for the Crippled Child ( $S / P / 1330)$ for their support for this study (MS, LR-F) and Professor B Meldrum for reading the manuscript. JEF is The British Journal of Anaesthesia Research Fellow, and ARH is supported by the Medical Research Council.

Received 28 June 1989 and in revised form 31 January 1990 Accepted 22 February 1990.

1 Myers RE, Yamaguchi M. Effects of serum glucose concentration on brain response to circulatory arrest. Abstr 52nd tration on brain response to circulatory arrest. Abstr 52nd Ann Meeting Amer Assoc Ne

2 Myers RE. A unitary theory of causation of anoxic and hypoxic brain pathology. In: Fahn S, Davis JN, Rowland LP, eds. Cerebral hypoxia and its consequences. New York: Raven Press, 1979:195.

3 Rehncrona S, Rosen I, Siesjo BK. Brain lactic acidosis and ischemic cell damage: 1 . Biochemistry and neurophysiology. J Cereb Blood Flow Metab 1981;1:297-311.

4 Kalimo H, Rehncrona S, Soderfeldt B, Olsson Y, Siesjo BK. Brain lactic acidosis and ischemic cell damage: 2 . Histopathology.J Cereb Blood Flow Metab 1981;1:313-27.

5 Mohr JP, Rubenstein L, Edlstein SZ, et al. Approaches to pathophysiology of stroke through the NINCDS Data Bank. In: Plum F, Pulsinelli W, eds. Cerebrovascular Raven Press, 1985:63.

6 Strong AJ, Miller SA, West IC. Protection of respiration of a crude mitochondrial preparation in cerebral ischaemia by crude mitochondrial preparation in cerebral ischaemia by control of blood

7 Robertson CS, Grossman RG. Protection against spinal cord ischemia with insulin induced hypoglycemia. Neurosurg 1987;67:739-44.

8 LeMay DR, Gehua L, Zelenock GB, D'Alecy LG. Insulin administration protects neurologic function in cerebral ischemia in rats. Stroke 1988;19:1411-9.

9 Olton DS. The radial arm maze as a tool in behavioura pharmacology. Physiol Behav 1987;40:793-7.

0 Davis HP, Tribuna J, Pulsinelli WA, Volpe BT. Reference and working memory of rats following hippocampal damage induced by transient forebrain ischemia. Physio Behav 1986;37:387-92.

11 Davis HP, Baranowski JR, Pulsinelli WA, Volpe BT. Retention of reference memory following ischemic hippocampal damage. Physiol Behav 1987;39:783-6.

12 Kagstrom E, Smith ML, Siesjo BK. Recirculation in the rat brain following incomplete ischemia. J Cereb Blood Flow Metab 1983;3:183-92. 
13 Prado R, Ginsberg MD, Dietrich WD, Watson BD, Busto R. Hyperglycemia increases infarct size in collaterally perfused but not end-arterial vascul

14 Ginsberg MD, Prado R, Dietrich WD, Busto R, Watson $B D$. Hyperglycemia reduces the extent of cerebral infarction in rats. Stroke 1987;18:570-4.

15 Swann JH, Evans MC, Meldrum BS. Long-term development of selective neuronal loss and the mechanism of protection by 2-amino 7-phosphonoheptanoate in a rat model of incomplete forebrain ischaemia. $J$ Cereb Blood Flow Metab 1988;8:64-78.

16 Barnes CA. Spacial learning and memory processes: the search for their neurobiological mechanisms in the rat. Trends Neurosci 1988;11:163-9.

17 Squire LR, Zola-Morgan S. Memory: brain systems and behaviour. Trends Neurosci 1988;11:170-5.

18 Rawlins JN. Associations across time: The hippocampus as a temporary memory store. Behav Brain Sci 1985;8:479-96.

19 Grotta JC, Pettigrew LC, Rosenbaum D, Reid C, Rhoades H, McCandless D. Efficacy and mechanism of action of a calcium channel blocker after global cerebral ischemia in rats. Stroke 1988;19:447-54.

20 Tamura A, Graham DI, McCulloch J, Teasdale GM. Foca cerebral ischaemia in the rat: 2 . Regional cerebral blood flow determined by [14C]iodoantipyrine autoradiography following middle cerebral artery occlusion. J Cereb Blood Flow Metab 1981;1:61-9.

21 Csiba L, Paschen W, Hossmann KA. A topographic quantitative method for measuring brain tissue $\mathrm{pH}$ under physiological and pathophysiological conditions. Brain Res 1983;289:334-7.

22 Benveniste H, Drejer J, Schousboe A, Diemer NH. Elevation of the extracellular concentrations of glutamate and aspartate in rat hippocampus during transient cerebra ischemia monitored by intracerebral microdialysis. Neurochem 1984;43:1369-74.

23 Collingridge GL, Kehl SJ, McLennan H. Excitatory amino acids in synaptic transmission in the Schaffer collateralcommissural pathway of the rat hippocampus. $J$ Physiol 1983;334:33-46.

24 Choi DW. Calcium mediated neurotoxicity: relationship to specific channel types and role in ischemic damage. Trends Neurosci 1988;11:465-9.

25 Suzuki R, Yamaguchi T, Li C-L, Klatzo I. The effects of 5 minute ischemia in Mongolian gerbils:II. Changes of spontaneous neuronal activity in cerebral cortex and CA1 sector hippocampus. Acta Neuropathol (Berl) 1983;60:217-22.

26 Harris RJ, Symon L, Branston NM, Bayhan M. Changes in extracellular calcium activity in cerebral ischaemia. Cereb Blood Flow Metab 1981;1:203-9.

27 Simon RP, Griffiths T, Evans MC, Swan JH, Meldrum BS.
Calcium overload in selectively vulnerable neurons of the hippocampus during and after ischemia: an electron microscopy study in the rat. $J$ Cereb Blood Flow Metab 1984;4:350-61.

28 Wieloch T, Lindvall O, Blomqvist P, Gage FH. Evidence for amelioration of ischaemic neuronal damage in the hippocampal formation by lesions of the perforant path. Neurol Res 1985;7:24-26.

29 Cummings JL, Tomiyasu U, Read S, Benson DF. Amnesia with hippocampal lesions after cardiopulmonary arrest. Neurology 1984;34:679-81.

30 Jorch G, Jorch N. Failure of autoregulation of cerebral blood flow in neonates studied by pulsed Doppler ultrasound of the internal carotid artery. Eur J Pediatr 1987;146:468-72.

31 Volpe BT, Hirst $W$. The characterization of an amnesic syndrome following hypoxic ischemic injury. Arch Neurol 1983;40:436-40.

32 Caronna JJ. Diagnosis, prognosis, and treatment of hypoxic coma. In: Fahn S, ed. Advances in neurology. Vol 26. New York: Raven Press, 1979:1

33 Siemkowicz E, Hansen AJ. Clinical restitution following cerebral ischemia in hypo-, normo- and hyperglycemic rats. Acta Neurol Scand 1977;58:1-8.

34 Havrankova J, Roth J, Brownstein M. Insulin receptors are widely distributed in the central nervous system of the rat. Nature 1978;272:827-9.

35 Klip A, Ramlal T, Cragoe EJ. Insulin-induced cytoplasmic alkalinization and glucose transport in muscle cells. $A m \mathrm{~J}$ Physiol 1986;250:C720-8.

36 Sutherland G, Lesiuk H, Bose R, Sima AA. Effect of mannitol, nimodipine, and indomethacin singly or in combination on cerebral ischemia in rats. Stroke 1988:19:571-8.

37 Lazarewicz JW, Pluta R, Salinska E, Puka M. Beneficial effect of nimodipine on metabolic and functional disturbances in rabbit hippocampus following complete cerebral ischemia. Stroke 1989;20:70-7.

38 Kempski O, Staub F, Jansen M, Schodel F, Baethmann A Glial swelling during extracellular acidosis in vitro. Stroke 1988;19:385-92.

39 Blaustein M. Calcium transport and buffering in neurones. Trends Neurosci 1988;11:438-43.

40 Hakim AM. Cerebral acidosis in focal ischemia: II. Nimodipine and verapamil normalize cerebral $\mathrm{pH}$ follow Nimodipine and verapamil normalize cerebral $\mathrm{pH}$ followBlood Flow Metab 1986;6:676-83.

41 Berger L, Hakim AM. Nimodipine prevents hyperglycemiainduced cerebral acidosis in middle cerebral artery occluded rats. J Cereb Blood Flow Metab 1989;9:58-64.

42 Pickard JD, Murray GD, Illingworth R, et al. Effect of ora nimodipine on cerebral infarction after subarachnoid haemorrhage: British aneurysm nimodipine trial. $\mathrm{Br} \mathrm{Med}$ $J$ 1989;298:636-42. 